\title{
Promiscuity among the MRAPs
}

\section{Adrian J L Clark and Li F Chan}

Centre for Endocrinology, William Harvey Research Institute, Barts \& the London School of Medicine \& Dentistry, Queen Mary University of London, Charterhouse Square, London, UK
Correspondence should be addressed to A J L Clark

Email

a.j.clark@qmul.ac.uk

\begin{abstract}
The melanocortin 2 receptor accessory protein (MRAP) was originally discovered to be an essential co-receptor for the ACTH receptor/melanocortin 2 receptor, and it physically interacts with this receptor and is required for receptor trafficking and ligand binding. A related molecule, MRAP2, is mainly expressed in the CNS and appears to have a role with the melanocortin 4 receptor. Consistent with this is the observation that a massively obese phenotype develops when the Mrap2 gene is deleted in mice. However, the characteristics of this phenotype differ from those of Mc4r-deleted mice and suggest that an additional role, possibly resulting from an interaction with other receptors is possible. In support of this, a functional interaction with the prokineticin receptors was recently reported. Evidence for other receptor interactions and aspects of the tissue distribution of MRAP and MRAP2 gene expression may indicate that these accessory proteins have a wider role than with the melanocortin receptors alone.
\end{abstract}
Key Words
- MRAP
- G protein-coupled receptors
- obesity
- knockout mouse

\section{Introduction}

Enormous financial and technical efforts are being expended in the drive to develop new and better drugs, many of which will be targeted at G protein-coupled receptors (GPCRs). Massive small molecule library screening requires the availability of a target that most closely resembles the physiological target, and yet, our understanding of the subtle regulatory factors that may influence these GPCRs is often not adequately represented in these screening procedures. It becomes particularly important therefore that efforts to properly understand any such receptor-associated factors are pursued. This view is well illustrated by considering the case of the melanocortin receptor accessory proteins (MRAPs).

\section{The discovery of MRAP}

An intact pituitary-adrenal axis is essential for normal healthy existence in mammals, and yet, is surprisingly dependent on a number of unique components encoded by single genes such as the proopiomelanocortin gene and the receptor for adrenocorticotropin (ACTH).

The ACTH receptor, properly known as the melanocortin 2 receptor (MC2R) was cloned in 1992, and it was immediately apparent that it was very difficult to express a functional receptor in transfected cells. In their original paper, Mountjoy and coworkers (Mountjoy et al. 1992) only reported MC2R expression in a cell line that expressed an endogenous MC1R. Using a green fluorescent protein-tagged MC2R, we demonstrated that the hybrid protein seemed to be retained in the endoplasmic reticulum and failed to reach the cell surface (Noon et al. 2002). Significantly, cell lines derived from the murine adrenocortical tumor Y1 line, which had developed unresponsiveness to ACTH action were found to be capable of expressing the transfected MC2R (Yang et al. 1997). This evidence suggested the existence of one or more adrenal-specific accessory factors that were required for receptor expression. http://jme.endocrinology-journals.org DOI: 10.1530/JME-17-0002
๑ 2017 Society for Endocrinology Printed in Great Britain
Published by Bioscientifica Ltd 
This hypothesis was shown to be correct in 2005 with the identification of a novel genetic cause of human ACTH insensitivity. Metherell and coworkers (Metherell et al. 2005) described a number of families in which a gene encoding a small single transmembrane domain protein was mutated. Co-transfection of this gene with the MC2R enabled a fully functional MC2R to be transported to the plasma membrane and to respond to ACTH stimulation by generating a cAMP signal. We named this the melanocortin 2 receptor accessory protein (MRAP) although, as will become apparent, this is occasionally and more helpfully referred to as MRAP1, and this terminology is used henceforth.

MRAP1 was most strongly expressed in adrenal tissues and cells, as well as in the gonad and adipose tissue. Human MRAP1 existed as one of two splice variants MRAP1 $\alpha$ and $\beta$ that had distinct $3^{\prime}$ ends encoding different C-termini. We found MRAP1 existed as a very stable dimer that was relatively resistant to dissociation by detergents and reducing agents (Cooray et al. 2008). Remarkably, Sebag and Hinkle (2007) demonstrated using a number of techniques that this was an antiparallel homodimer in which one N-terminus was extracellular and the other intracellular. This structure is represented in the Fig. 1. This seems to be a unique phenomenon in eukaryotic biology, although this topology has probably only very rarely been sought in other dimeric proteins.

It now appears that MRAP1 plays several key roles in the expression of the MC2R. The MRAP1 dimer complexes with the receptor at the endoplasmic reticulum, and this event is required for the receptor to be trafficked to the cell surface. During processing, MRAP1 may also influence MC2R glycosylation (Kay et al. 2015). At the cell surface, MRAP1 is required for ACTH to generate a G proteinmediated signal (predominantly via $\mathrm{Go}_{\mathrm{s}}$ ), and this is probably because the N-terminus of MRAP1 contributes to the recognition and binding of ACTH (Malik et al. 2015).

\section{MRAP2}

In our original paper describing MRAP1, we also pointed to the existence of a gene predicted to encode a related protein, which we called MRAP2 on the basis of its relatedness to MRAP1 (Metherell et al. 2005). As with MRAP, MRAP2 also naturally exists as an antiparallel homodimer but with a distinct tissue expression pattern principally in many areas of the CNS (Chan et al. 2009, Asai et al. 2013, Chaly et al. 2016). We demonstrated that MRAP2 interacted with all five of the melanocortin receptors in transfected cells (as does MRAP1) (Chan et al. 2009).

\section{Extracellular surface}

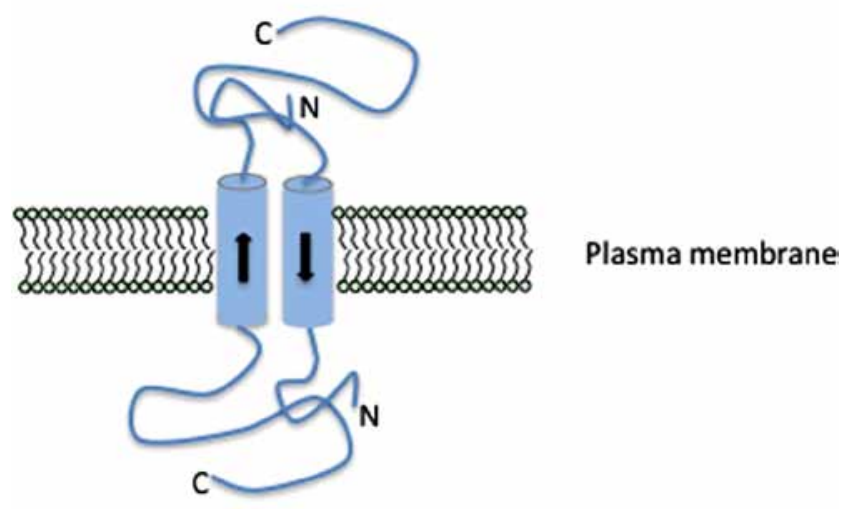

Intracellular surface

Figure 1

Schematic representation of the antiparallel topology of the MRAP proteins that result in one $\mathrm{N}$-terminus and one $\mathrm{C}$-terminus being presented on each surface of the plasma membrane for each dimer.

MRAP2 supports trafficking of MC2R, although ACTH responsiveness is markedly weaker, such that substantially greater, supraphysiological concentrations of ACTH are required to activate this receptor (Gorrigan et al. 2011). Both MRAPs partially inhibited the signaling of the MC1R, MC3R, MC4R and MC5R (Chan et al. 2009). In the case of the inhibition of the MC5R, there is evidence to suggest that MRAP2 inhibits MC5R homodimerization (Sebag \& Hinkle 2009). Agulleiro and coworkers (Agulleiro et al. 2013) demonstrated that the zebrafish MRAP2a, but not the related MRAP2b, was able to increase the responsiveness of $\mathrm{Zf} \mathrm{MC} 4 \mathrm{R}$ to $\mathrm{ACTH}$ without altering the MSH response, and it is conceivable that modulation of agonist selectivity by MRAP2 could occur with other receptors or in other species.

As both MRAP2 and the MC4R are expressed in the paraventricular nucleus of the hypothalamus, where it is well established that the MC4R has a key role in regulating satiety, the possibility that MRAP2 has a part to play in MC4R function and appetite regulation arises. Asai and coworkers (Asai et al. 2013) demonstrated that under certain transfection conditions, in which a 6:1 ratio of MRAP2 to MC4R expression vector was used, MRAP2 reduced the constitutive activity of the MC4R and enhanced the maximal effect of $\alpha$-MSH stimulation. As this results in a greater change in signal for a given change in agonist dosage, this can be interpreted as 'sensitizing' the MC4R to agonist. It is notable that the effect on constitutive activity was similar to a non-significant trend

Published by Bioscientifica Ltd. 
previously observed by Chan and coworkers (Chan et al. 2009), although this directly contrasted with the opposite effect (an increase in constitutive activity in the presence of MRAP2) described by Kay and coworkers (Kay et al. 2015). These contrasts should prompt caution in interpreting heterologous cell transient expression studies, particularly when discrepant concentrations of expression vector are required to demonstrate a result.

Arguably, a more physiological examination of this hypothesis is provided by the development of the MRAP2 gene deleted mouse (Mrap2-/-), which exhibited a severe obesity phenotype (Asai et al. 2013). A hypomorph Mrap2 mouse generated using a different strategy and only expressing a fraction of normal Mrap2 mRNA resulted in a very similar phenotype (Novoselova et al. 2016), as did deletion of Mrap2 exclusively in the Sim1 neurons of the paraventricular nucleus - implying that the mechanism was dependent solely on these neurons in the hypothalamus (Asai et al. 2013). These observations are highly suggestive of a vital role of MRAP2 with the MC4R.

However, closer examination of the data shows that the phenotypes of the Mc4r-/- mice and the Mrap2-/mice are distinct. In particular, the synthetic MC4R agonist, MTII, is fully effective in Mrap2-/- animals in contrast to its complete inactivity in $\mathrm{Mc} 4 \mathrm{r}-\mathrm{-}-$ mice (Asai et al. 2013), implying that the $\alpha$-MSH-induced satiety pathways are fully functional in Mrap2-knockout animals. Mc4r-/- mice are hyperphagic and show reduced energy expenditure and insulin resistance, whereas no disturbance of food intake, energy expenditure or insulin and glucose regulation was seen in the Mrap2-/- mice. In fact male hypomorphic Mrap2 mice show increased beam-breaking activity compared to that in wild-type littermates. Bone mineral density is unchanged in hypomorphic Mrap2 mice in contrast to increased density seen in Mc4r-/- animals (Novoselova et al. 2016). These distinctions are summarized in Table 1.

Table 1 Comparison of the metabolic phenotype of the Mc4r-/- and Mrap2-/- mice.

\begin{tabular}{|c|c|c|}
\hline Parameter & Mc4r-I-mouse & Mrap2-I- mouse \\
\hline Weight & ++++ & +++ \\
\hline Hyperphagia & $>20 \% \uparrow$ & No change \\
\hline Energy expenditure & $\downarrow$ & No change \\
\hline Movement & No change & $\uparrow$ \\
\hline Insulin & $+++\uparrow$ & No change \\
\hline Glucose tolerance & $\downarrow$ at $10-14$ weeks & $\begin{array}{l}\text { No difference } \\
12-28 \text { weeks }\end{array}$ \\
\hline Response to MTII & No response & $\begin{array}{l}\text { Reduced feeding, } \\
\text { same as wild type }\end{array}$ \\
\hline Bone density & $\uparrow$ & No change \\
\hline
\end{tabular}

http://jme.endocrinology-journals.org DOI: 10.1530/JME-17-0002
(C) 2017 Society for Endocrinology Printed in Great Britain
Thus, the evidence seems to suggest that although MRAP2 has a significant role in body weight maintenance and that this role is delivered through the paraventricular nucleus of the hypothalamus, any influence on MC4R function is probably complicated by a role with other appetite-regulating pathways.

\section{Are the MRAPs promiscuous?}

Phylogenetic studies demonstrate fairly conclusively that MRAP2 is the ancestral gene, being identifiable in the sea lamprey (Petromyzon marinus). Evidence for MRAP first arises at the time of the development of the teleosts (Takifugu rubripes) or possibly in elasmobranchs including the elephant shark (Callorhinchus milii), and from this time, both genes exist with a key role for MRAP in supporting MC2R function emerging by the time of the evolution of the zebrafish (Danio rerio) (Västermark \& Schiöth 2011). It is conceivable that although MRAP seems to have a vital role with the MC2R in mammals, there is no strong evidence that MRAP2 functions are restricted to the melanocortin receptors.

In support of the idea of a broader role for the MRAPs, it is notable that Chan and coworkers showed that MRAP2 interacted with the $\beta_{2}$-adrenergic receptor in transfected cells without apparently influencing its signaling capacity, but not with the AT1 angiotensin receptor (Chan et al. 2009). More recently, Chaly and coworkers (Chaly et al. 2016) reported an interaction between the prokineticin 1 and 2 receptors (PKR1 and PKR2) and MRAP2, and an inhibitory effect of MRAP2 when expressed in vitro with these receptors (although a 10:1 ratio of MRAP2 to PKR1 or PKR2 expression vector was used). These findings are particularly interesting in the light of the Mrap2-knockout mouse studies. PKR2 is expressed in the arcuate nucleus and mediates a satiety effect that Chaly et al. showed is independent of the MC4R anorectic effect. If MRAP2 has a physiological role in suppressing the PKR1 signal, one might expect the Mrap2-knockout animal to show a lean phenotype, but it is argued that when this action is compounded with the potent reduction in satiety resulting from impaired MC4R action, the distinct phenotype observed by Asai and coworkers and Novoselova and coworkers results (Asai et al. 2013, Novoselova et al. 2016). Attractive as this hypothesis is, some questions remain, such as why the Mrap2-knockout phenotype seems to arise from the paraventricular nucleus (as shown by the Sim1 conditional knockout), whereas the PKR1 action occurs in the arcuate nucleus.

Published by Bioscientifica Ltd. 
Thus, evidence is beginning to emerge that MRAP2 may be more promiscuous than originally thought in having a range of receptor partners. Humans with a defective MRAP1 gene exhibit a very clear adrenal failure phenotype without other consistent clinical problems. However, MRAP1 is expressed in tissues with little or no MC2R expression and the possibility of non-MC2R consequences may have to await the characterization of the Mrap -/- mouse.

This evidence of an expanding and more promiscuous role for the MRAPs resembles the way in which the RAMP proteins were initially believed to be calcitonin-like receptor-specific accessory proteins, but which are now well recognized to have a broader range of functions with several members of the Class 2 GPCRs (Hay et al. 2006). Further dissection of the Mrap2-knockout model, the development and characterization of an Mrap1 knockout and careful in vitro identification of further interacting partners of the MRAPs may reveal novel aspects of physiology, which may be important in supporting efforts to develop drugs that target these pathways.

\section{Declaration of interest}

The authors declare that there is no conflict of interest that could be perceived as prejudicing the impartiality of this review.

\section{Funding}

This research did not receive any specific grant from any funding agency in the public, commercial or not-for-profit sector. L F C is supported by an MRC/ Academy of Medical Sciences Clinician Scientist Fellowship (G0802796).

\section{References}

Agulleiro MJ, Cortés R, Fernández-Durán B, Navarro S, Guillot R, Meimaridou E, Clark AJ \& Cerdá-Reverter JM 2013 Melanocortin 4 receptor becomes an ACTH receptor by coexpression of melanocortin receptor accessory protein 2. Molecular Endocrinology 27 1934-1945. (doi:10.1210/me.2013-1099)

Asai M, Ramachandrappa S, Joachim M, Shen Y, Zhang R, Nuthalapati N, Ramanathan V, Strochlic DE, Ferket P, Linhart K, et al. 2013 Loss of function of the melanocortin 2 receptor accessory protein 2 is associated with mammalian obesity. Science 341 275-278. (doi:10.1126/science.1233000)

Chaly AL, Srisai D, Gardner EE \& Sebag JA 2016 The melanocortin receptor accessory protein 2 promotes food intake through inhibition of the prokineticin receptor-1. eLife 5 e12397. (doi:10.7554/elife.12397)

Chan LF, Webb TR, Chung TT, Meimaridou E, Cooray SN, Guasti L, Chapple JP, Egertová M, Elphick MR, Cheetham ME, et al. 2009
MRAP and MRAP2 are bidirectional regulators of the melanocortin receptor family. PNAS 106 6146-6151. (doi:10.1073/ pnas.0809918106)

Cooray SN, Almiro Do Vale I, Leung KY, Webb TR, Chapple JP, Egertová M, Cheetham ME, Elphick MR \& Clark AJ 2008 The melanocortin 2 receptor accessory protein exists as a homodimer and is essential for the function of the melanocortin 2 receptor in the mouse Y1 cell line. Endocrinology 149 1935-1941. (doi:10.1210/ en.2007-1463)

Gorrigan RJ, Guasti L, King P, Clark AJ \& Chan LF 2011 Localisation of the melanocortin-2-receptor and its accessory proteins in the developing and adult adrenal gland. Journal of Molecular Endocrinology 46 227-232. (doi:10.1530/JME-11-0011)

Hay DL, Poyner DR \& Sexton PM 2006 GPCR modulation by RAMPs. Pharmacology and Therapeutics 109 173-197. (doi:10.1016/j. pharmthera.2005.06.015)

Kay EI, Botha R, Montgomery JM \& Mountjoy KG 2015 hMRAP $\alpha$, but not hMRAP2, enhances hMC4R constitutive activity in HEK293 cells and this is not dependent on hMRAP $\alpha$ induced changes in hMC4R complex N-linked glycosylation. PLoS ONE 10 e0140320. (doi:10.1371/journal.pone.0140320)

Malik S, Dolan TM, Maben ZJ \& Hinkle PM 2015 Adrenocorticotropic hormone $(\mathrm{ACTH})$ responses require actions of the melanocortin-2 receptor accessory protein on the extracellular surface of the plasma membrane. Journal of Biological Chemistry 290 27972-27985. (doi:10.1074/jbc.m115.668491)

Metherell LA, Chapple JP, Cooray S, David A, Becker C, Rüschendorf F, Naville D, Begeot M, Khoo B, Nürnberg P, et al. 2005 Mutations in MRAP, encoding a new interacting partner of the ACTH receptor, cause familial glucocorticoid deficiency type 2. Nature Genetics 37 166-170. (doi:10.1038/ng1501)

Mountjoy KG, Robbins LS, Mortrud MT \& Cone RD 1992 The cloning of a family of genes that encode the melanocortin receptors. Science 257 1248-1251. (doi:10.1126/science.1325670)

Noon LA, Franklin JM, King PJ, Goulding NJ, Hunyady L \& Clark AJ 2002 Failed export of the adrenocorticotrophin receptor from the endoplasmic reticulum in non-adrenal cells: evidence in support of a requirement for a specific adrenal accessory factor. Journal of Endocrinology 174 17-25. (doi:10.1677/joe.0.1740017)

Novoselova TV, Larder R, Rimmington D, Lelliott C, Wynn EH, Gorrigan RJ, Tate PH, Guasti L, Sanger Mouse Genetics Project, O'Rahilly S, et al. 2016 Loss of Mrap2 is associated with Sim1 deficiency and increased circulating cholesterol. Journal of Endocrinology 230 13-26. (doi:10.1530/JOE-16-0057)

Sebag JA \& Hinkle PM 2007 Melanocortin-2 receptor accessory protein MRAP forms antiparallel homodimers. PNAS $10420244-20249$. (doi:10.1073/pnas.0708916105)

Sebag JA \& Hinkle PM 2009 Opposite effects of the melanocortin-2 (MC2) receptor accessory protein MRAP on MC2 and MC5 receptor dimerization and trafficking. Journal of Biological Chemistry 284 22641-22648. (doi:10.1074/jbc.M109.022400)

Västermark A \& Schiöth HB 2011 The early origin of melanocortin receptors, agouti-related peptide, agouti signalling peptide, and melanocortin receptor-accessory proteins, with emphasis on pufferfishes, elephant shark, lampreys, and amphioxus. European Journal of Pharmacology 660 61-69. (doi:10.1016/j. ejphar.2010.10.106)

Yang YK, Ollmann MM, Wilson BD, Dickinson C, Yamada T, Barsh GS \& Gantz I 1997 Effects of recombinant agouti-signaling protein on melanocortin action. Molecular Endocrinology 11 274-280. (doi:10.1210/mend.11.3.9898)

Received in final form 15 February 2017

Accepted 17 February 2017

Accepted Preprint published online 17 February 2017 http://jme.endocrinology-journals.org

DOI: 10.1530/JME-17-0002
() 2017 Society for Endocrinology Printed in Great Britain
Published by Bioscientifica Ltd 